\title{
sciendo
}

\section{Discriminant analysis for defining quality of life patients with comorbid pathology of osteoarthrosis}

\author{
Tatyana STROHONOVA \\ Zaporizhzhia State Medical University, Zaporizhzhia /Ukraine \\ strogonova@meta.ua \\ Maria BONDAR \\ MI «Zaporozhye Primary Health Care Center N 1 Zaporizhzhia /Ukraine \\ Suren VARZHAPETIAN \\ Zaporizhzhya Medical Academy of Postgraduate Education
}

\begin{abstract}
There has been a shift in medicine from relying on clinical biomarkers to including patientreported outcome measures. From a healthcare perspective, health-related quality of life (HRQOL) measures can be used to enhance patient care and reducing treatment cost for patients. Given the possible importance of Medical Outcome Study in medicine, and the conflicting reports in literature about its use in healthcare, it is important to identify its utility within the medical community.

In this study 150 people were recruited prospectively from patients at the Hospital and the emergency center №1 in Zaporizhzhya, Ukraine. Four groups were formed. The inclusion criteria to group were different comorbid pathology of osteoarthrosis. We assessed patients HRQOL SF-36 SF-36 changes before and after pharmacotherapy (over 1 year), than it were compared with the control group.

The validity of the construct has been analyzed by discriminant analysis. To assess SF-36 ability identifying discriminating functions were developed, determine its prediction value, define which scales of SF-36 are the best predictors for every groups. In addition, canonical analysis demonstrates SF-36 ability to estimate effect of pharmacotherapy.

Statistical analysis show that all indices quality of life through SF - 36 scales except of third (physical role functioning, physical functioning, emotional role functioning) have prognostic value ( $p>0.05)$ and validity of SF-39 scales for examination of the patients with coexisting disease is statistically significant $(p<0.05)$.
\end{abstract}

Keywords: osteoarthritis, comorbidity, hypertension, discriminant analysis, quality of life, SF-36, validity, canonical analysis

\section{Introduction}

There has been a shift in medicine from relying on clinical biomarkers to including patientreported outcome measures.

Although many health researches focuses on objective outcome measures such as biochemical and psychological parameters defined through clinical assessment, there is an increasing emphasis on self-reported measures of health status and health-related quality of life (HRQOL). Using HRQOL reflects the importance of considering the patients' point of view and the multidimensional nature of health [1-3]. 


\section{Literature review}

Clinicians and public health officials have used Questionnaire Medical Outcome Study Short Form - 36 (SF - 36) as an outcome measure [1-3] and prognostic instrument to estimate the effects of chronic illness, treatments, and short- and long-term disabilities of patients with rheumatoid arthritis [2], gastroenteritis [3], stroke [4, 7], multiple sclerosis [5], hypertensive heart disease [6], schizophrenia and a lot of other.

While there are roughly 2000 articles about using of SF-36 to measure quality of life for different pathology, methodological development in this area is still ongoing. In all research they used statistical analysis to estimate reliability and validity of SF-36. To evaluate effect of treatment using SF-36 researchers used variance analysis [2], Mann-Whitney test [6], Student's test and Chi-squared test $\chi 2$.

\section{Methodology}

In this study 150 people were recruited prospectively from patients at the Hospital and the emergency center №1 in Zaporizhzhya, Ukraine. Four groups were formed (each group consist of 30 patients). All groups were comparable for age and gender. The inclusion criteria to group were: one of the diagnosis osteoarthrosis (OA), hyperpiesis (HP), osteoarthritis with occurring co- hyperpiesia (HP+OA) and osteoarthritis with NSAID-induced gastropathy $(\mathrm{HP}+\mathrm{OA}+\mathrm{GP})$. The control group was composed of 30 healthy people with no history of osteoarthrosis.

We assessed patients HRQOL changes before and after pharmacotherapy (over 1 year), than it were compared with the control group. HRQOL changes was determined in SF36 scores by eight scaled: vitality (VT), physical functioning (PF), bodily pain (BP), general health perception ns $(\mathrm{GH})$, physical role functioning (RP), emotional role functioning (RE), social role functioning (SF), mental health (MH).

The validity of the construct has been analyzed by discriminant analysis. To assess SF36 ability identifying discriminating functions were developed, determine its prediction value, define which scales of SF-36 are the best predictors for every groups. In addition, canonical analysis demonstrates SF-36 ability to estimate effect of pharmacotherapy. These analyses were conducted using Statistica 10.

\section{Results and discussions}

As mentioned above, in order to estimate validity of SF-36 there is no ability to use traditional approach. We could not assess association between scales of generic (SF-36) and some specialized questionnaires $(\mathrm{OA})$ using correlation methods due to the absence of special questionnaire for $\mathrm{OA}$ with comorbidity.

We used discriminant analysis to estimate ability of self-reported questionnaires to identifying different form of comorbidity. For eight variable vitality (VT), physical functioning (PF), bodily pain (BP), general health perceptions (GH), physical role functioning (RP), emotional role functioning (RE), social role functioning (SF), mental health (MH) discriminant function were developed. Analysis of this function present at Table 1. 
Table 1. Discriminant function analysis of health related life's quality measuring through the SF-36 for patients suffering from osteoarthrosis with different comorbidity

\begin{tabular}{|c|c|c|c|c|c|c|}
\hline Показник & $\begin{array}{l}\text { Wilks' - } \\
\text { Lambda }\end{array}$ & $\begin{array}{l}\text { Partial - } \\
\text { Lambda }\end{array}$ & $\begin{array}{l}\text { F-remove - } \\
(4,138)\end{array}$ & p-value & Toler. & $\begin{array}{l}\text { 1-Toler. - } \\
\text { (R-Sqr.) }\end{array}$ \\
\hline \multicolumn{7}{|c|}{ Before tretment Wilks' Lambda: ,13718 approx. F $(32,510)=11,386 ; \mathrm{P}<0,0000$} \\
\hline $\mathrm{PF}$ & 0,1503 & 0,9128 & 3,2966 & 0,0129 & 0,7178 & 0,2822 \\
\hline $\mathrm{RP}$ & 0,1467 & 0,9351 & 2,3926 & 0,0536 & 0,7950 & 0,2050 \\
\hline BP & 0,2165 & 0,6337 & 19,9443 & 0,0000 & 0,6494 & 0,3506 \\
\hline $\mathrm{GH}$ & 0,1574 & 0,8716 & 5,0823 & 0,0008 & 0,4704 & 0,5296 \\
\hline VT & 0,1579 & 0,8686 & 5,2191 & 0,0006 & 0,4457 & 0,5543 \\
\hline SF & 0,1603 & 0,8560 & 5,8016 & 0,0002 & 0,5221 & 0,4779 \\
\hline RE & 0,1560 & 0,8795 & 4,7273 & 0,0013 & 0,8044 & 0,1956 \\
\hline MH & 0,1500 & 0,9147 & 3,2164 & 0,0147 & 0,4308 & 0,5692 \\
\hline \multicolumn{7}{|c|}{ After treatment Wilks' Lambda: ,18239 approx. F $(32,510)=9,3539 ; \mathrm{P}<0,0000$} \\
\hline \begin{tabular}{l|l}
$\mathrm{PF}$ & \\
\end{tabular} & 0,1884 & 0,9680 & 1,1395 & 0,3406 & 0,6477 & 0,3523 \\
\hline $\mathrm{RP}$ & 0,1997 & 0,9132 & 3,2784 & 0,0133 & 0,8562 & 0,1438 \\
\hline BP & 0,2684 & 0,6794 & 16,2786 & 0,0000 & 0,5325 & 0,4675 \\
\hline GH & 0,2272 & 0,8028 & 8,4760 & 0,0000 & 0,5244 & 0,4756 \\
\hline VT & 0,2095 & 0,8707 & 5,1244 & 0,0007 & 0,5153 & 0,4847 \\
\hline SF & 0,1991 & 0,9162 & 3,1544 & 0,0162 & 0,4498 & 0,5502 \\
\hline $\mathrm{RE}$ & 0,1917 & 0,9513 & 1,7675 & 0,1389 & 0,7754 & 0,2246 \\
\hline $\mathrm{MH}$ & 0,2697 & 0,6761 & 16,5250 & 0,0000 & 0,4204 & 0,5796 \\
\hline
\end{tabular}

As shown in the table 1, all indices of quality of life through SF - 36 scales but RP (physical role functioning) before treatment and PF (physical functioning), RE (emotional role functioning) after treatment are the variables of discriminant functions. Thus, all indices quality of life through SF - 36 scales except of third (RP, PF, RE) have prognostic value ( $>0.05$ ) for distinguishing types of OA comorbidities and validity of SF-39 scales for examination of the OA patients with coexisting disease is statistically significant.

To check validity of the SF-36 questioner for the assessment of quality of life in OA with HP and G obtained discriminant functions were applied to the array of data and the classification correctness was appraised. After defining a classification functions, the data were classified according to that rule, and sample classification rate was obtained.

The result of this analysis figures in Table 2 as classification matrix, where the general percent of the correctly defined cases can be considered as the most relevant value of discrimination.

Table 2. Classification matrix of discriminant analysis

\begin{tabular}{|c|c|c|c|c|c|c|}
\hline GROUP & $\begin{array}{c}\text { Percent - } \\
\text { Correct }\end{array}$ & $\begin{array}{l}\text { Control } \\
P=0,20\end{array}$ & $\begin{array}{c}\text { HP } \\
\mathrm{P}=0,20\end{array}$ & $\begin{array}{c}\mathrm{OA} \\
\mathrm{P}=0,20\end{array}$ & $\begin{array}{l}\mathrm{OA}+\mathrm{HP} \\
\mathrm{P}=0,20\end{array}$ & $\begin{array}{c}\mathrm{OA}+\mathrm{HP}+\mathrm{G} \\
\mathrm{P}=0,20\end{array}$ \\
\hline \multicolumn{7}{|c|}{ Before treatment } \\
\hline Control & 90,00 & 27 & 2 & 1 & 0 & 0 \\
\hline HP & 76,67 & 5 & 23 & 0 & 2 & 0 \\
\hline $\mathrm{OA}$ & 53,33 & 2 & 0 & 16 & 9 & 3 \\
\hline $\mathrm{OA}+\mathrm{HP}$ & 56,67 & 0 & 0 & 8 & 17 & 5 \\
\hline $\mathrm{OA}+\mathrm{HP}+\mathrm{G}$ & 66,67 & 0 & 0 & 1 & 9 & 20 \\
\hline Total & 68,67 & 34 & 25 & 26 & 37 & 28 \\
\hline
\end{tabular}




\begin{tabular}{|c|c|c|c|c|c|c|}
\hline GROUP & $\begin{array}{c}\text { Percent - } \\
\text { Correct }\end{array}$ & $\begin{array}{l}\text { Control } \\
P=0,20\end{array}$ & $\begin{array}{c}\mathrm{HP} \\
\mathrm{P}=0,20\end{array}$ & $\begin{array}{c}\mathrm{OA} \\
\mathrm{P}=0,20\end{array}$ & $\begin{array}{l}\mathrm{OA}+\mathrm{HP} \\
\mathrm{P}=0,20\end{array}$ & $\begin{array}{c}\mathrm{OA}+\mathrm{HP}+\mathrm{G} \\
\mathrm{P}=0,20\end{array}$ \\
\hline \multicolumn{7}{|c|}{ After treatment } \\
\hline Control & 60,00 & 18 & 4 & 5 & 1 & 2 \\
\hline $\mathrm{HP}$ & 83,33 & 3 & 25 & 0 & 1 & 1 \\
\hline $\mathrm{OA}$ & 66,67 & 3 & 1 & 20 & 4 & 2 \\
\hline $\mathrm{OA}+\mathrm{HP}$ & 56,67 & 3 & 7 & 0 & 17 & 3 \\
\hline $\mathrm{OA}+\mathrm{HP}+\mathrm{G}$ & 73,33 & 3 & 1 & 0 & 4 & 22 \\
\hline Total & 68,00 & 30 & 38 & 25 & 27 & 30 \\
\hline
\end{tabular}

The data in Table 2 shows how accurately the patients with different OA comorbidity were classified into these groups. The discrimination functions excels at identifying healthy patients $(90 \%)$. Total percentage of correctly predicted cases before $(68,7 \%)$ and after $(68 \%)$ treatment reveals prognostic power of SF-36 indices for classifying different co-occurring OA diseases. In addition, this analysis allows proving the difference between the well-being of patients with different type of OA co-occurring pathology.

Further, we performed the canonical correlation analysis that determined the successive functions and canonical roots (Root1, Root2). The coefficients of canonical analysis do not tell between which of the groups the respective functions discriminate. To identify the nature of the discrimination for each discriminant (canonical) function we visualized how the two functions discriminate between 5 groups by plotting the individual scores for the two discriminant functions before (Fig1.a) and after treatment (Fig.1.b).
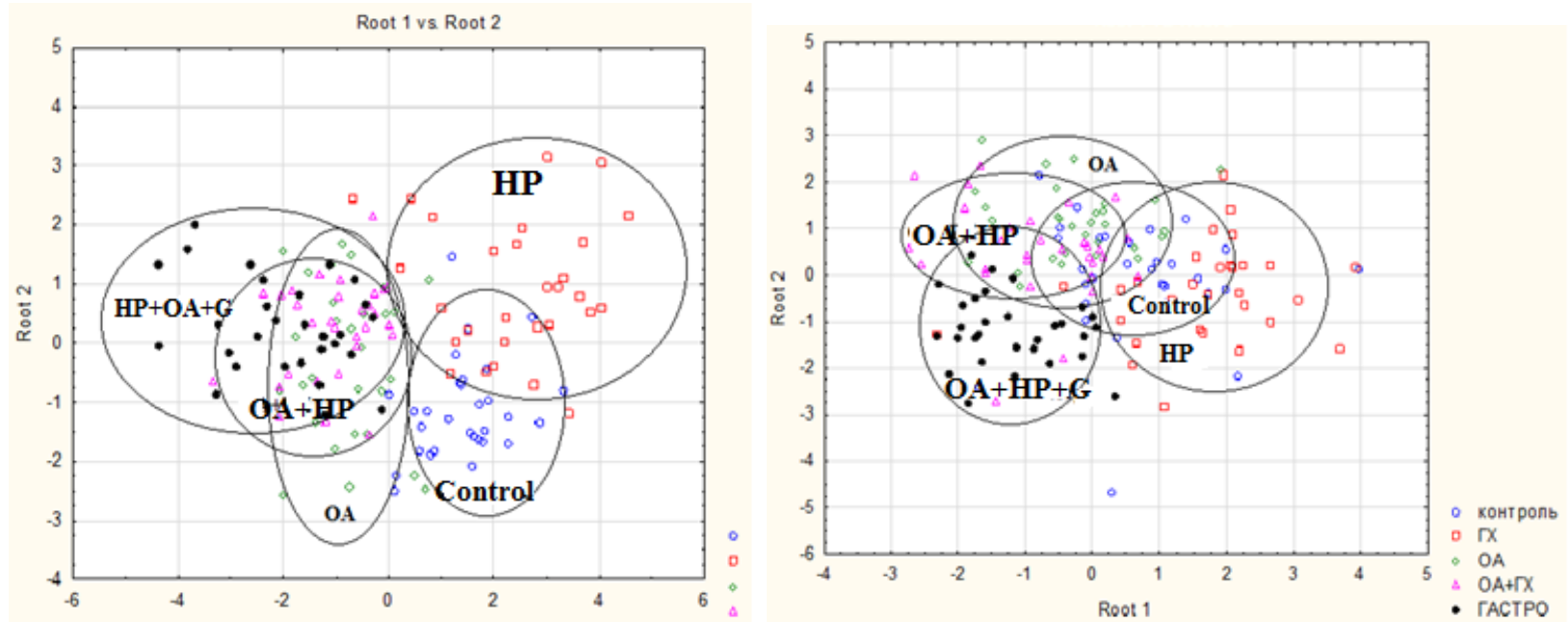

Fig.1 Scatterplot of response to treatment profiles within two-dimensional canonical space for patients with osteoarthrosis with coexisting disorders a-before treatment b-after treatment

Source: Authors' own research

In the Fig. $1 \mathrm{a}$ is scatterplot of patients distribution, profiling within two-dimensional canonical space with canonical roots $R_{1}=0,856$ and $R_{2}=0,568(\mathrm{p}<0,01)$ for patients with coexisting osteoarthrosis disorders. Group means are centroids. Differences in location of centroids show dimensions along which groups differ. As seen in Fig.1-a comorbidity groups 
$\mathrm{HP}+\mathrm{OA}+\mathrm{G}$ and $\mathrm{OA}+\mathrm{HP}$ tend to have non-intersecting ellipses with centroid of control group what mean they have significantly different degree of severity.

Canonical roots $R_{1}=0,722$ and $R_{2}=0,626$ are statistically significant too ( $\left.\mathrm{p}<0.01\right)$. The canonical plot based on the roots in the Fig.1-b shows how to change pattern of points after treatment. All groups "close approaches" to each other that all have common points. This pattern could be interpreted as improvement of patient's state, lessening of severity and abatement after treatment.

\section{Conclusion}

By methods of statistics (discriminant analysis) we proved validity of SF-36 questioner and show that the SF-36 scale could be used for differentiation state of patients with comorbid $\mathrm{OA}$ pathologies and estimation response to treatment of these patients.

\section{References}

Brazier J., Harper R., Jones N. et al. Validating the SF-36 health survey questionnaire: new outcome measure for primary care // BMJ. - 1992. - Vol. 305. - P. 160-164.

Hurst N., Ruta D., Kind P. Comparison of the MOS short-form-12 (SF-12) health status questionnaire with the SF-36 in patients with rheumatoid arthritis // Br. J. Rheumatol. - 1998. - Vol 37,N 8. - P. 862-869.

Svedlund J., Posserud I., Abrahamsson H. Health-related quality of life in patients attending a gastroenterology outpatient clinic: functional disorders versus organic diseases // Clin. Gastroenterol. Hepatol. - 2006. -Vol. 4, N 2. - P. 187-195.

Hobart J., Williams L., Moran K., Thompson A. Quality of life measurement after stroke: uses and abuses of the SF-36 // Stroke. - 2002. - Vol. 33. - P. 1349-1356.

Nortvedt M., Riise T., Myhr K., Nyland H. Performance of the SF-36, SF-12, and RAND-36 summary scales in a multiple sclerosis population // Med. Care. 2000. - Vol. 38. - P. 1022-1028.

Kitaoka M., Mitoma J., Asakura H. et al. The relationship between hypertension and healthrelated quality of life: adjusted by chronic pain, chronic diseases, and life habits in the general middle-aged population in Japan // Environ Health Prev. Med. - 2016. - Vol. 21. - P. 1-22.

Muus I., Williams L., Ringsberg K. Validation of the Stroke Specific Quality of Life Scale (SSQOL): test of reliability and validity of the Danish version (SS-QOL-DK) // Clin. Rehabil. -2007. - Vol. 21, N. 7. - P. 620-6277. 